\title{
Determination of carbohydrates in the herbal antidiabetic mixtures by GC-MC
}

\author{
ALONA SAVYCH ${ }^{1 *}$ \\ SVITLANA MARCHYSHYN ${ }^{1}$ \\ IVANNA MILIAN $^{2}$ \\ ${ }^{1}$ Department of Pharmacognosy \\ with Medical Botany \\ I. Horbachevsky Ternopil National \\ Medical University, Ternopil \\ 46001, Ukraine \\ ${ }^{2}$ Department of General Chemistry \\ I. Horbachevsky Ternopil National \\ Medical University, Ternopil \\ 46001, Ukraine
}

\begin{abstract}
Due to the wide range of biologically active substances, the herbal mixtures can influence the development of diabetes mellitus and its complications. Carbohydrates attract particular attention due to their hypoglycemic, hypolipidemic, anticholesterolemic, antioxidant, antiinflammatory and detoxifying activities. The aim of this study was to investigate the content of carbohydrates through their monomeric composition in the herbal mixture samples: a) Urtica dioica leaf, Cichorium intybus roots, Rosa majalis fruits, Elymys repens rhizome, Taraxacum officinale roots, b) Arctium lappa roots, Elymys repens rhizome, Zea mays columns with stigmas, Helichrysum arenarium flowers, Rosa majalis fruits, c) Inula helenium rhizome with roots, Helichrysi arenarium flowers, Zea mays columns with stigmas, Origanum vulgare herb, Rosa majalis fruits, Taraxacum officinale roots, d) Cichorium intybus roots, Elymys repens rhizome, Helichrysum arenarium flowers, Rosa majalis fruits, Zea mays columns with stigmas and e) Urtica dioica leaf, Taraxacum officinale roots, Vaccinium myrtillus leaf, Rosa majalis fruits, Mentha piperita herb, which were used in Ukrainian folk medicine for the prevention and treatment of diabetes mellitus type 2 .

The carbohydrates were separated by gas chromatography-mass spectrometry after conversion into volatile aldononitrile acetate derivatives. The monomeric composition of polysaccharides was studied after their hydrolysis to form monosaccharides and polyalcohols.

Quantitative analyses of free carbohydrates showed that the predominant sugars were fructose, glucose and disaccharide - sucrose, in all samples. Concerning the determination of polysaccharide monomers after hydrolysis, glucose was the most abundant in all samples. The chromatographic study revealed a number of polyalcohols that are important for the treatment and prevention of progression of diabetes mellitus and its complications, namely, mannitol, pinitol and myo-inositol.
\end{abstract}

Keywords: carbohydrates, herbal antidiabetic mixtures, GC-MS, monosaccharides
Accepted August 21, 2020

Published online September 10, 2020

Diabetes mellitus is one of WHO's priority issues. It requires immediate resolution as the epidemiological situation is gaining alarming proportions - the number of diabetic

\footnotetext{
*Correspondence; e-mail: alonasavych@gmail.com
} 
patients is increasing every year along with the number of deaths and disabilities due to the development of micro- and macro-angiopathies (1). According to the official report from the International Diabetes Federation (2019), an increase in the incidence of diabetes is projected to be 1.5 times by 2030 in the world, which will amount to more than 500 thousand patients (2). Therefore, the optimization of pharmacotherapy along with the search and study of new drugs for the prevention and treatment of this disease and its complications is a top issue of pharmacy and medicine.

One of these areas is using herbal remedies, either as monotherapy for the prevention or in the mild stages of the disease or in the combination with traditional therapy in more severe forms of the disease. Phytotherapy is a justified method for the prevention and treatment because it has some advantages, such as relatively low toxicity, mild pharmacological effects and possibility to be used for long periods without significant side-effects, and it often well combines with synthetic drugs (3-5). The combinations of different medicinal plants deserve particular attention. Herbal mixtures are expected to have several biologically active substances with a wide range of pharmacological actions and a variety of mechanisms for influencing the development of diabetes (pathogenesis of which involves the development of insulin resistance, relative insulin deficiency, which leads to the decrease of secretory activity of $\beta$-cells of the pancreatic gland) and diabetic angiopathies (inactivation of the antioxidant protection system, activation of lipid peroxidation and development of oxidative stress) (6-8).

For this purpose, it is advisable to study the phytochemical composition, namely, to identify the carbohydrates, in free and bound form, in the herbal mixtures used in folk medicine for the prevention and treatment of diabetes mellitus type 2 in Ukraine (9).

Carbohydrates obtained from plants are very important active substances for the prevention and treatment of diabetes mellitus and diabetic angiopathies due to their hypoglycemic, hypolipidemic, anticholesterolemic, antioxidant, antiinflammatory and detoxifying activities (10-13). Polysaccharides stimulate the growth of beneficial bacteria in the colon, including Bifidobacteria and Lactobacilli, thereby modulating the composition of microflora. This creates an environment that protects against pathogens, toxins and free radicals formed from lipid peroxidation $(14,15)$. Powerful antioxidant properties of polysaccharides in a number of studies in vivo and in vitro, whose mechanism of action is not quite understood, have been observed $(14,16,17)$. Plant carbohydrates have the ability to regulate lipid metabolism by lowering triglycerides and cholesterol, a disorder that occurs in diabetes and leads to the development of cardiovascular diseases and microcirculatory complications - diabetic nephropathy, neuropathy and retinopathy, the formation of diabetic foot $(18,19)$. The carbohydrates achieve their hypoglycemic activity through increasing the insulin secretion, inhibition of glucagon secretion, stimulation of $\beta$-cells proliferation and neogenesis $(11,13)$. In addition, they also show antiinflammatory properties, which are manifested by reducing the parameters of inflammation such as edema, leukocyte migration and nociception (20). All these properties make the carbohydrates an important group of substances for the prevention and treatment of diabetes mellitus and its extremely dangerous complications.

The aim of this study was to investigate the content of carbohydrates in the free form and their monomeric composition after hydrolysis, in several herbal mixtures (samples 1-5) with reliable hypoglycemic activity established during the screening tests (21-23). 


\section{EXPERIMENTAL}

\section{Plant materials}

The herbal raw materials harvested from June to August 2019 in the Ternopil region and Carpathians (Vaccinium myrtillus leaf) (Ukraine) were used. After harvesting, the raw materials were dried, crushed and stored according to the general GACP requirements (24). The plants were identified in the Department of Pharmacognosy with Medical Botany, I. Horbachevsky Ternopil National Medical University, Ternopil, Ukraine. The voucher specimens of herbal raw materials have been deposited in the departmental herbarium for future records.

For the study, five different herbal mixtures with reliable hypoglycemic activity established during the screening tests (21-23) were used. The composition of the mixtures is given in Table I.

Table I. Composition of the herbal mixtures

\begin{tabular}{|c|c|c|c|}
\hline Herbal mixture & Herbal drug component & Portion in the mixture $(\%)$ & Relative ratio \\
\hline \multirow{5}{*}{ Sample 1} & Urtica dioica leaf & 26.3 & 5 \\
\hline & Cichorium intybus roots & 26.3 & 5 \\
\hline & Rosa majalis fruits & 21.1 & 4 \\
\hline & Elymys repens rhizome & 15.8 & 3 \\
\hline & Taraxacum officinale roots & 10.5 & 2 \\
\hline \multirow{5}{*}{ Sample 2} & Arctium lappa roots & 26.3 & 5 \\
\hline & Elymys repens rhizome & 26.3 & 5 \\
\hline & Zea mays columns with stigmas & 21.1 & 4 \\
\hline & Helichrysum arenarium flowers & 15.8 & 3 \\
\hline & Rosa majalis fruits & 10.5 & 2 \\
\hline \multirow{6}{*}{ Sample 3} & Inula helenium rhizome with roots & 10.0 & 1 \\
\hline & Helichrysi arenarium flowers & 20.0 & 2 \\
\hline & Zea mays columns with stigmas & 20.0 & 2 \\
\hline & Origanum vulgari herb & 20.0 & 2 \\
\hline & Rosa majalis fruits & 20.0 & 2 \\
\hline & Taraxacum officinale roots & 10.0 & 1 \\
\hline \multirow{5}{*}{ Sample 4} & Cichorium intybus roots & 26.3 & 5 \\
\hline & Elymys repens rhizome & 26.3 & 5 \\
\hline & Helichrysum arenarium flowers & 21.1 & 4 \\
\hline & Rosa majalis fruits & 15.8 & 3 \\
\hline & Zea mays columns with stigmas & 10.5 & 2 \\
\hline \multirow{5}{*}{ Sample 5} & Urtica dioica leaf & 20.0 & 1 \\
\hline & Taraxacum officinale roots & 20.0 & 1 \\
\hline & Vaccinium myrtillus leaf & 20.0 & 1 \\
\hline & Rosa majalis fruits & 20.0 & 1 \\
\hline & Mentha piperita herb & 20.0 & 1 \\
\hline
\end{tabular}




\section{Reagents}

All applied reagents were of analytical grade ( $\geq 95 \%$ purity). Standard reagents, including D-mannose, L-rhamnose, D-ribose, D-galactose, D-xylose, D-arabinose, D-glucose, D-fructose, saccharose, cellobiose and D-sorbitol, were purchased from Sigma-Aldrich Chemical Co. (USA), as well as methanol, trifluoroacetic acid, hydroxylamine hydrochloride, pyridine, dichloroethane, hydrochloride acid, heptanes and ethyl acetate. Water used in the studies was produced by the MilliQ Gradient water deionization system (Millipore, USA).

\section{Conditions of gas chromatography-mass spectrometry}

The content of carbohydrates in the samples of the herbal mixtures was studied by gas chromatography-mass spectrometry (GC-MS) using the Agilent Technologies (USA) system, model 6890N/5973inert (6890 gas chromatography with mass spectrometry detector 5973) and capillary column HP- $5 \mathrm{~ms}(30 \mathrm{~m} \times 0.25 \mathrm{~mm} \times 0.25 \mathrm{~mm}$, Agilent Technologies). The evaporator temperature was $250{ }^{\circ} \mathrm{C}$, the interface temperature $280^{\circ} \mathrm{C}$. The separation was performed in the mode of temperature programming - the oven temperature was initially set to $160^{\circ} \mathrm{C}$, held for $8 \mathrm{~min}$, then ramped at the rate of $5^{\circ} \mathrm{C} \mathrm{min}^{-1}$ to $240{ }^{\circ} \mathrm{C}$ and finally held at this temperature for $6 \mathrm{~min}$. Injections of $1 \mu \mathrm{L}$ were made in the split mode 1:50. The detection was performed in the SCAN mode in the range of 38-400 m/z; the ionization energy was $70 \mathrm{eV}$ and the scan rate was $2.9 \mathrm{~s}$ per scan. The carrier gas (helium) flow rate through the column was $1.2 \mathrm{~mL} \mathrm{~min}^{-1}(25,26)$.

\section{Extraction of carbohydrates and hydrolysis}

The samples of herbal raw materials were ground into a powder by laboratory mill, then about $500 \mathrm{mg}$ (accurately weighed) was selected and placed into a round-bottom flask with $10.0 \mathrm{~mL}$ of methanol ( $80 \%$ ) and internal standard - sorbitol (500 $\mu \mathrm{g}$ per sample). The extractions were carried out in an ultrasonic water bath at $80^{\circ} \mathrm{C}$ for 4 hours. The resulting extracts were centrifuged at $3000 \mathrm{rpm}$ and the supernatants were evaporated to dryness on a rotary evaporator. One mg of the extract was used for hydrolysis of carbohydrates with $5 \mathrm{~mL}$ of $2 \mathrm{~mol} \mathrm{~L}^{-1}$ trifluoroacetic acid at $100{ }^{\circ} \mathrm{C}$ for 6 hours. The obtained hydrolyzed solution was evaporated to dryness under $45^{\circ} \mathrm{C}$ and then $1 \mathrm{~mL}$ methanol was added for further evaporation and complete removal of trifluoroacetic acid. The rest of the extract was used for the determination of free carbohydrates (26).

\section{Derivatization}

To obtain the aldononitrile monosaccharide derivatives, the dried hydrolysates of the extracts were taken and $0.3 \mathrm{~mL}$ of a derivatization reagent $\left[32 \mathrm{mg} \mathrm{mL}^{-1}\right.$ hydroxylamine hydrochloride in the mixture of pyridine/methanol $(4: 1, V / V)]$ was added. The samples were incubated in a preheated water bath shaker at $75^{\circ} \mathrm{C}$ for $25 \mathrm{~min}$. Then, for acetylation of aldonitrile derivatives, $1 \mathrm{~mL}$ of acetic anhydride was subsequently added to the samples and incubated at $75{ }^{\circ} \mathrm{C}$ for $15 \mathrm{~min}$. To the resulting reaction mixture, $2 \mathrm{~mL}$ of dichloroethane was added. The excess of the derivatization reagents was removed by the double extraction with $1 \mathrm{~mol} \mathrm{~L}^{-1} \mathrm{HCl}$ and water. The dichloroethane phase was dried and dissolved in $300 \mu \mathrm{L}$ of the mixture of heptane/ethyl acetate $(1: 1, V / V)(27)$. 


\section{Identification and quantitation by GC-MS}

To identify the components, the obtained spectra were analyzed by comparing the retention times with the data of the mass spectra libraries NIST 02 (26). Quantitative analyses were performed by the method of internal standards.

Under normal conditions of derivatization, the ketone carbohydrate (fructose) is converted into an aldo-carbohydrate (glucose) (27). According to this technique, fructose after derivatization gives 2 peaks, which are summed up during calculations. The chromatograms show two peaks (12 \& 13) belonging to fructose.

\section{Method preliminary validation}

The method was validated for linearity, limits of detection and quantitation $(L O D$, $L O Q)$, and precision.

All reference standards showed acceptable linearity $\left(R^{2}>0.99\right)$ within the concentration range $1.25-25 \mathrm{mg} \mathrm{mL}^{-1}$. Linearity testing was based on five concentration levels and repeated with the same samples after a complete restart of the system with the removal and re-installation of the column. Limits of detection and quantification were estimated as 3 and 10 times the signal-to-noise ratio $(S / N)$ for each carbohydrate. Considering all carbohydrates, in general, $L O D$ ranged $0.9-2.9 \mu \mathrm{g} \mathrm{mL}^{-1}$ and $L O Q 3.5-15.3 \mu \mathrm{g} \mathrm{mL} \mathrm{L}^{-1}$.

Injection repeatability was determined by a five-fold injection of the same sample. To determine intra-day precision, five samples of the same concentration of each reference standard were single injected to calculate RSD. Inter-day precision for the day of sample preparation and the two following days was specified by injecting five samples of each reference standard, once each, on all three days. Intra- and inter-day RSD ranged from 4.8 to $6.6 \%$.

\section{RESULTS AND DISCUSSION}

Results of qualitative and quantitative analyses of free and bound carbohydrates in the samples of the herbal antidiabetic mixtures 1-5 are shown in Figs. 1-10 and Table II.

\section{Qualitative analyses}

During GC-MC, the highest number of free carbohydrates was identified (11 carbohydrates) in sample 3 (Fig. 3). Samples 4 and 5 contained nine carbohydrates in free form (Figs. 4, 5). The lowest number of free carbohydrates (8 carbohydrates) was found in samples 1 and 2 (Figs. 1, 2). Among the detected free carbohydrates, polyalcohols predominated in all samples of the herbal antidiabetic mixtures. Five polyalcohols in samples 2 and 3 , four polyalcohols in samples 1 and 2 and three polyalcohols in sample 5 were identified. In addition, four free monosaccharides in the samples 3 and 5 , three monosaccharides in the samples 1 and 4 and two monosaccharides in sample 2 were detected. Also, it was established that samples 2, 3 and 5 contain two disaccharides, sucrose and cellobiose, and samples 1 and 4 only one disaccharide, sucrose (Figs. 1, 3, 5, 7, 9). 


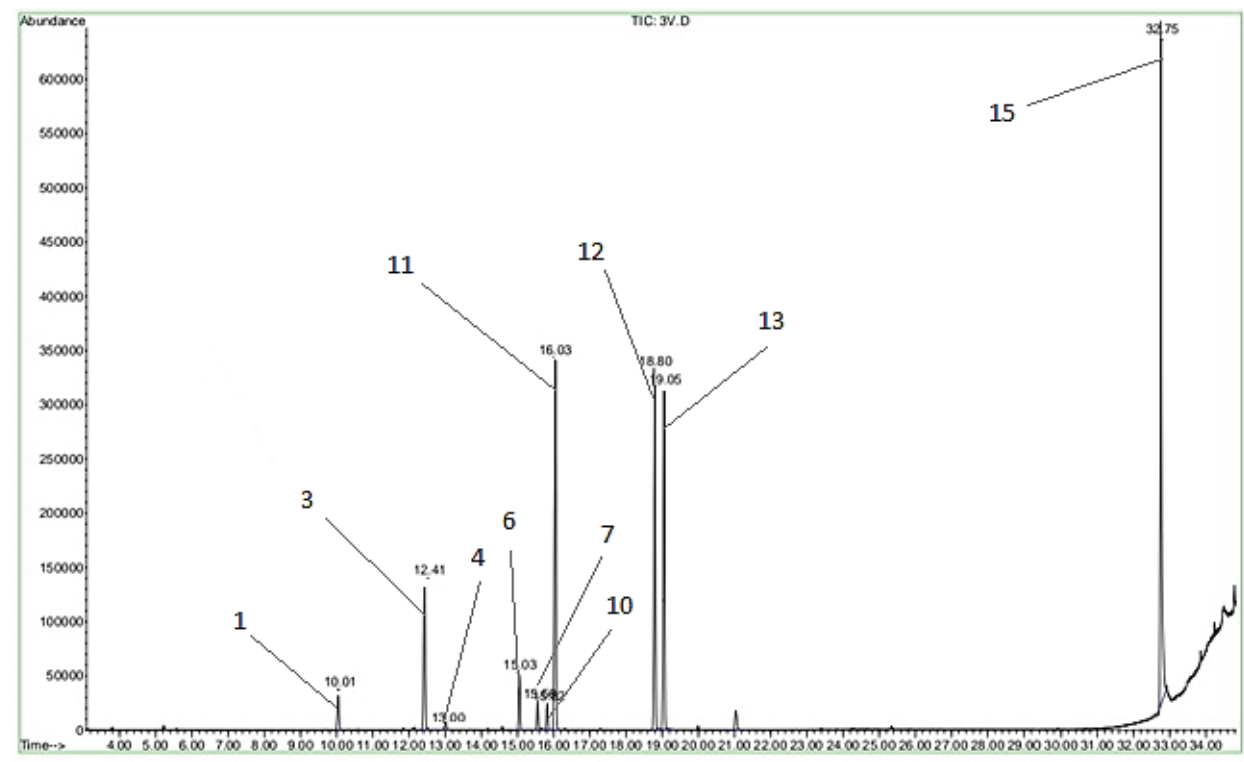

Fig. 1. GC-MS chromatogram of free carbohydrates in sample 1, after derivatization. The keys to the peaks are in Table II.

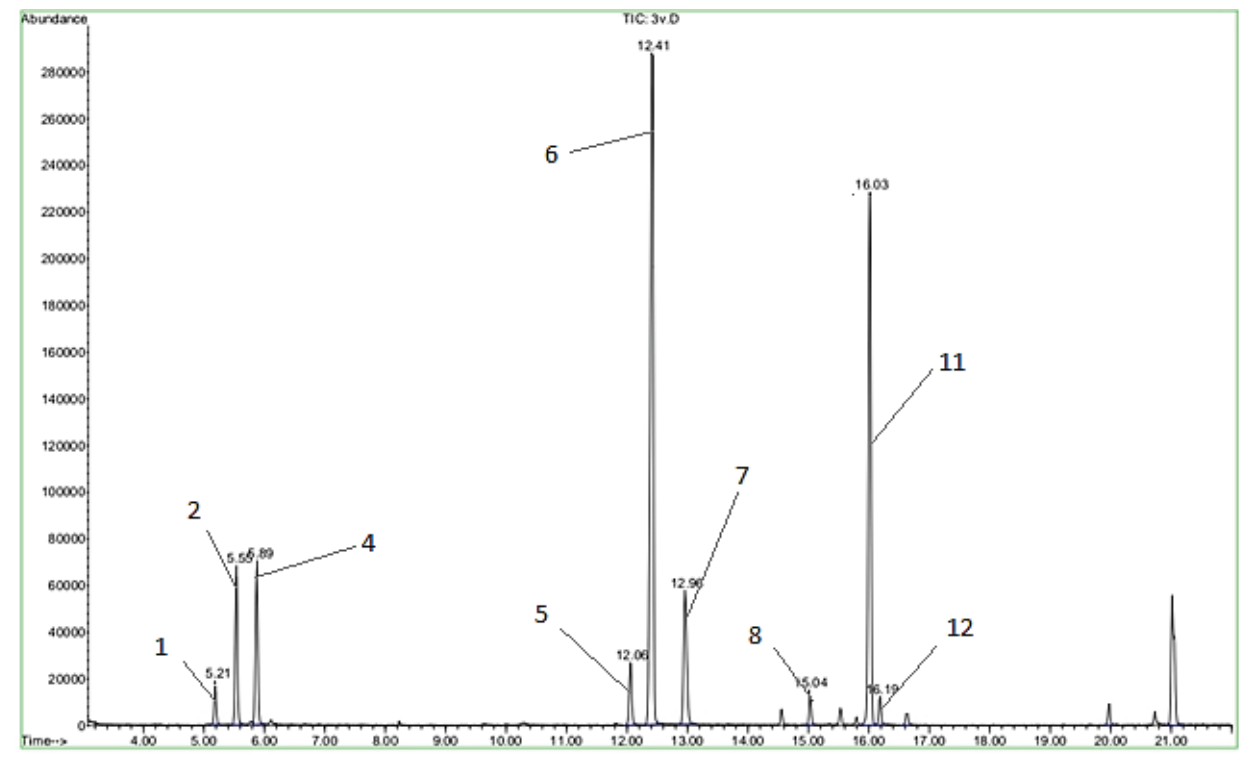

Fig. 2. GC-MS chromatogram of carbohydrates after hydrolysis of sample 1, after derivatization. The keys to the peaks are in Table II. 


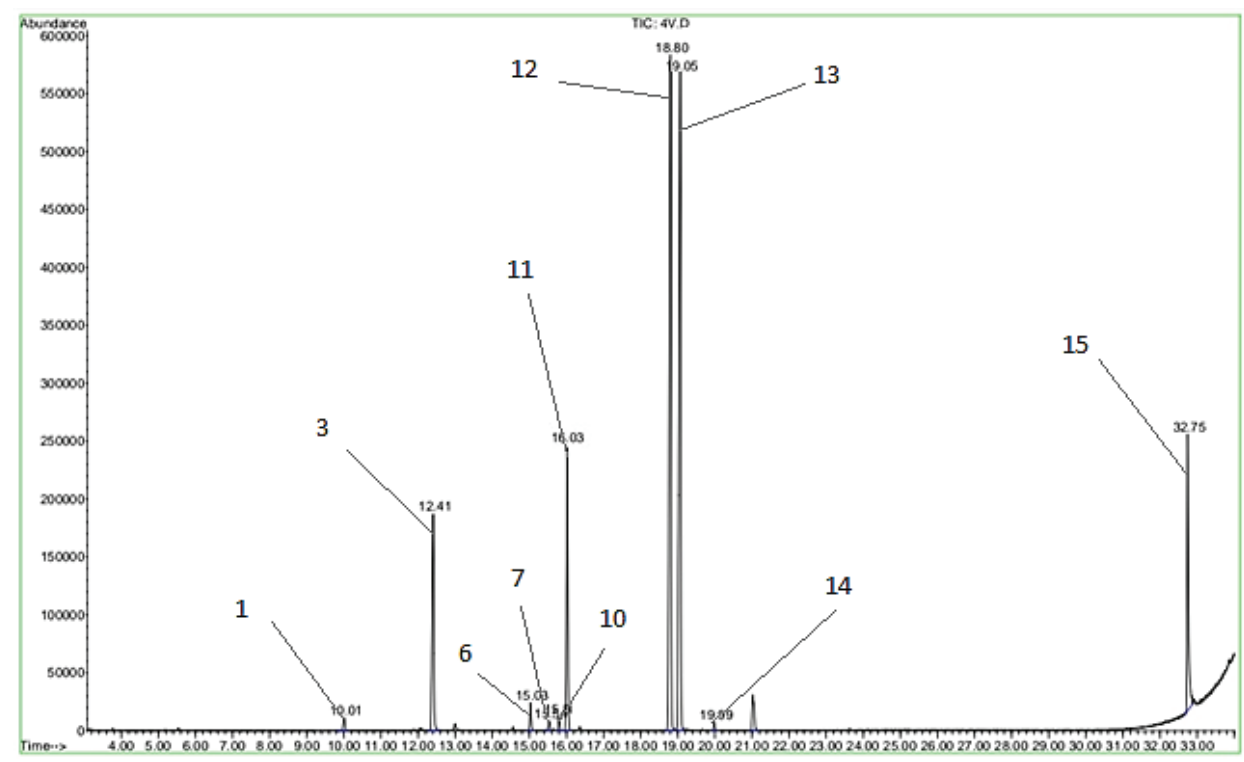

Fig. 3. GC-MS chromatogram of free carbohydrates in sample 2, after derivatization. The keys to the peaks are in Table II.

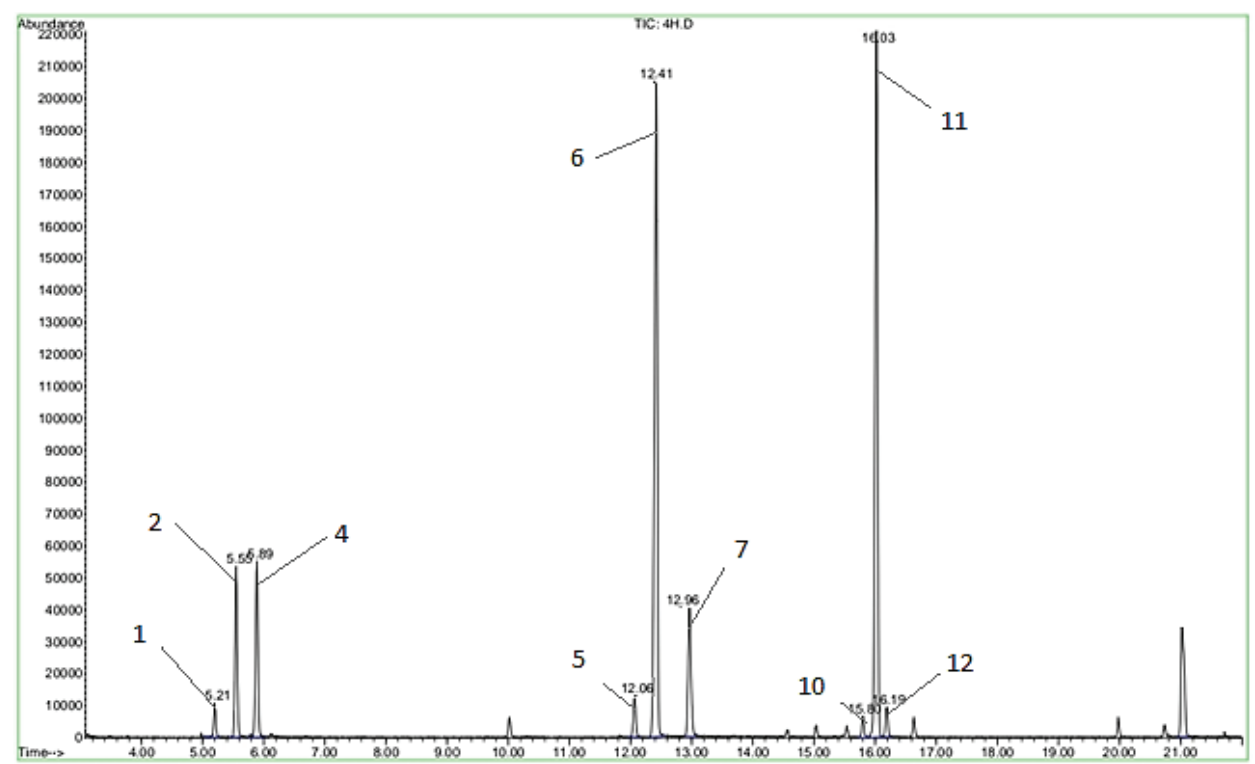

Fig. 4. GC-MS chromatogram of carbohydrates after hydrolysis of sample 2, after derivatization. The keys to the peaks are in Table II. 


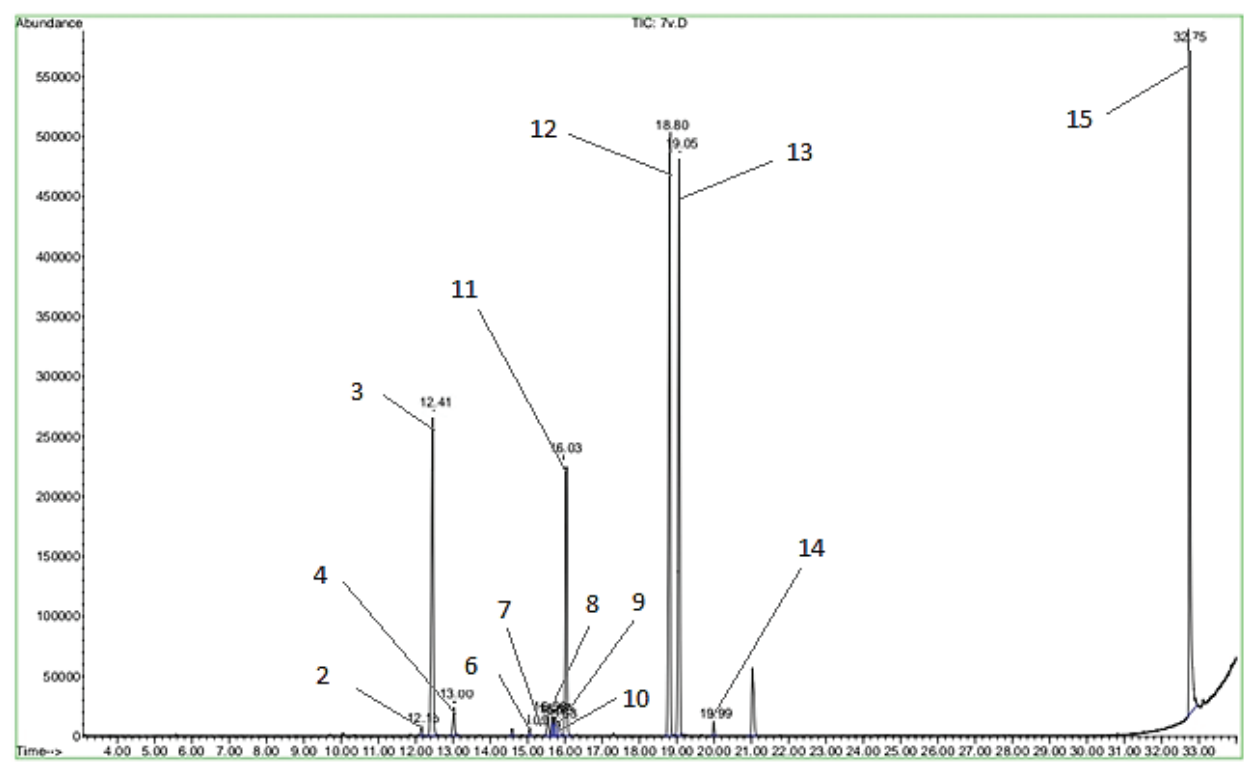

Fig. 5. GC-MS chromatogram of free carbohydrates in sample 3, after derivatization. The keys to the peaks are in Table II.

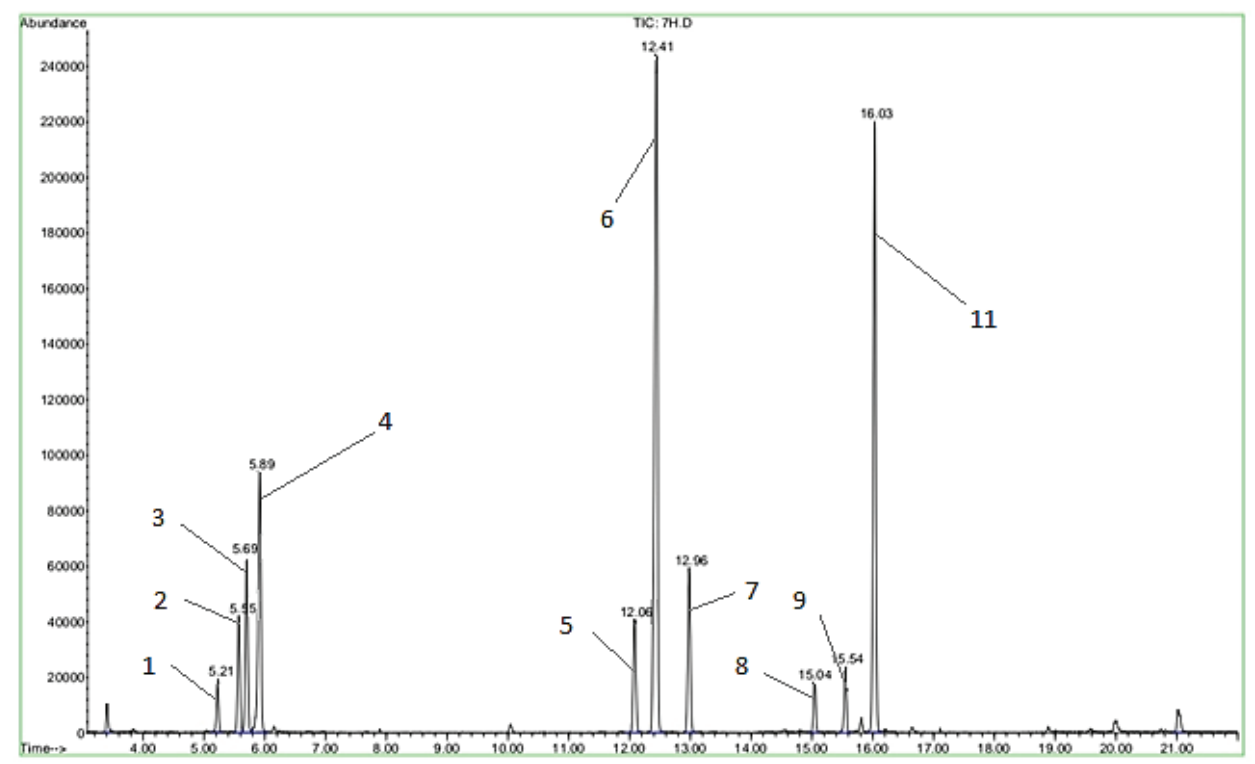

Fig. 6. GC-MS chromatogram of carbohydrates after hydrolysis of sample 3, after derivatization. The keys to the peaks are in Table II.+ 


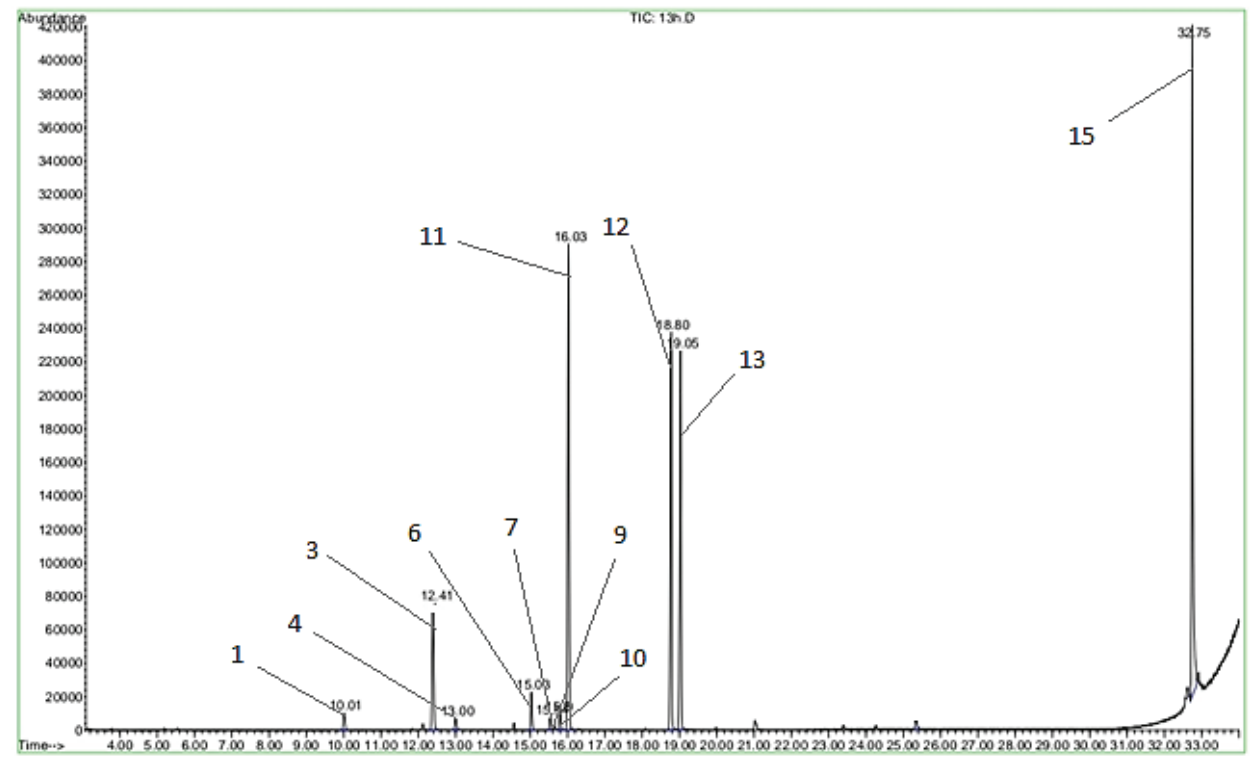

Fig. 7. GC-MS chromatogram of free carbohydrates in sample 4, after derivatization. The keys to the peaks are in Table II.

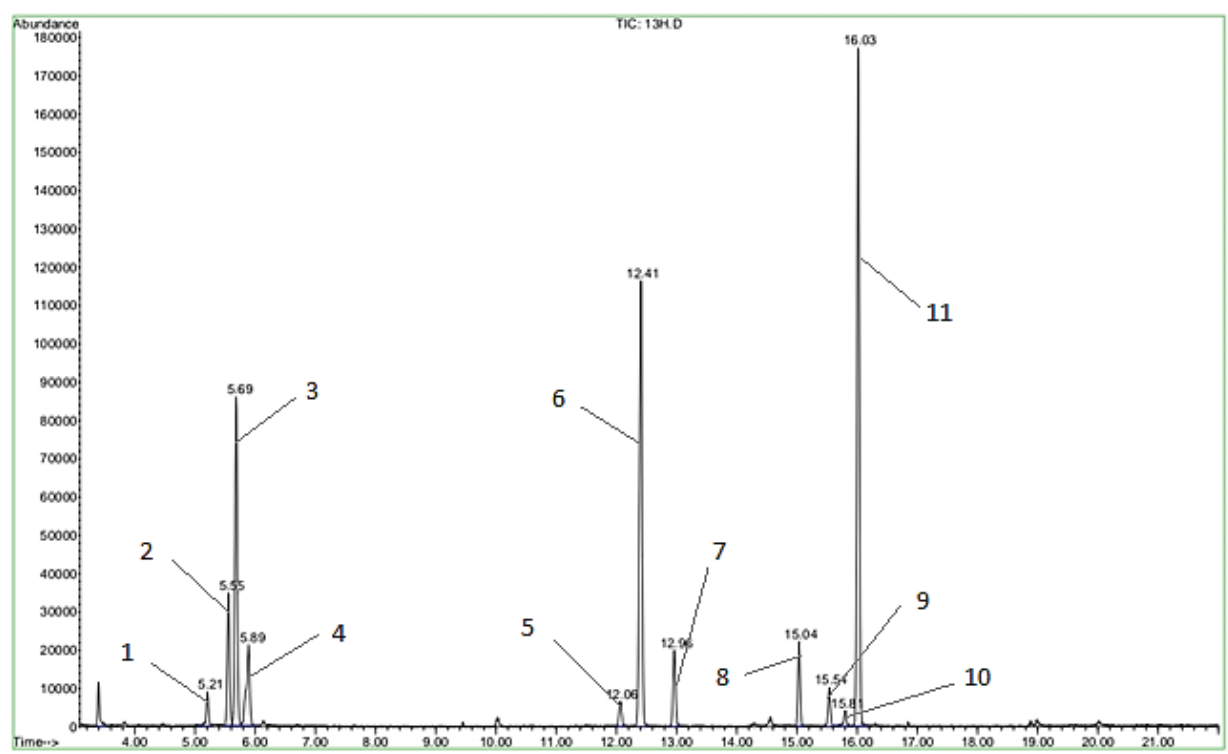

Fig. 8. GC-MS chromatogram of carbohydrates after hydrolysis of sample 4, after derivatization. The keys to the peaks are in Table II. 


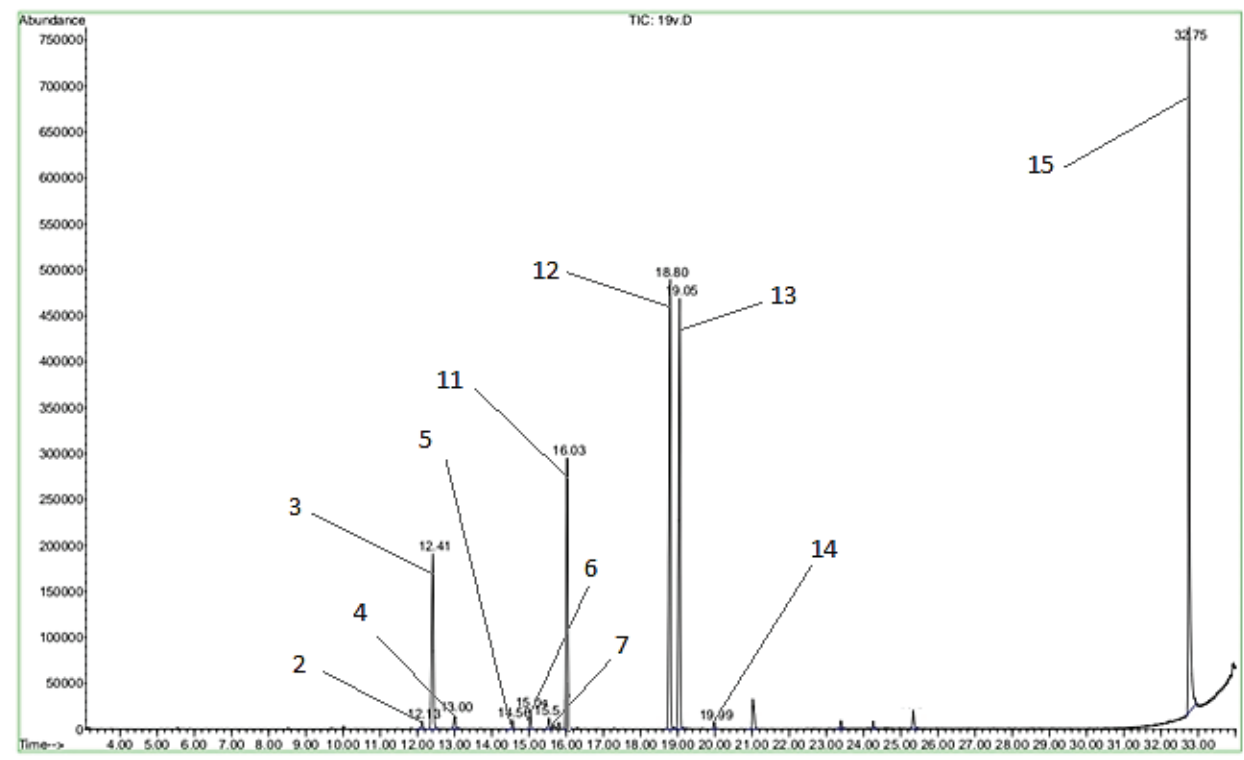

Fig. 9. GC-MS chromatogram of free carbohydrates in sample 5, after derivatization. The keys to the peaks are in Table II.

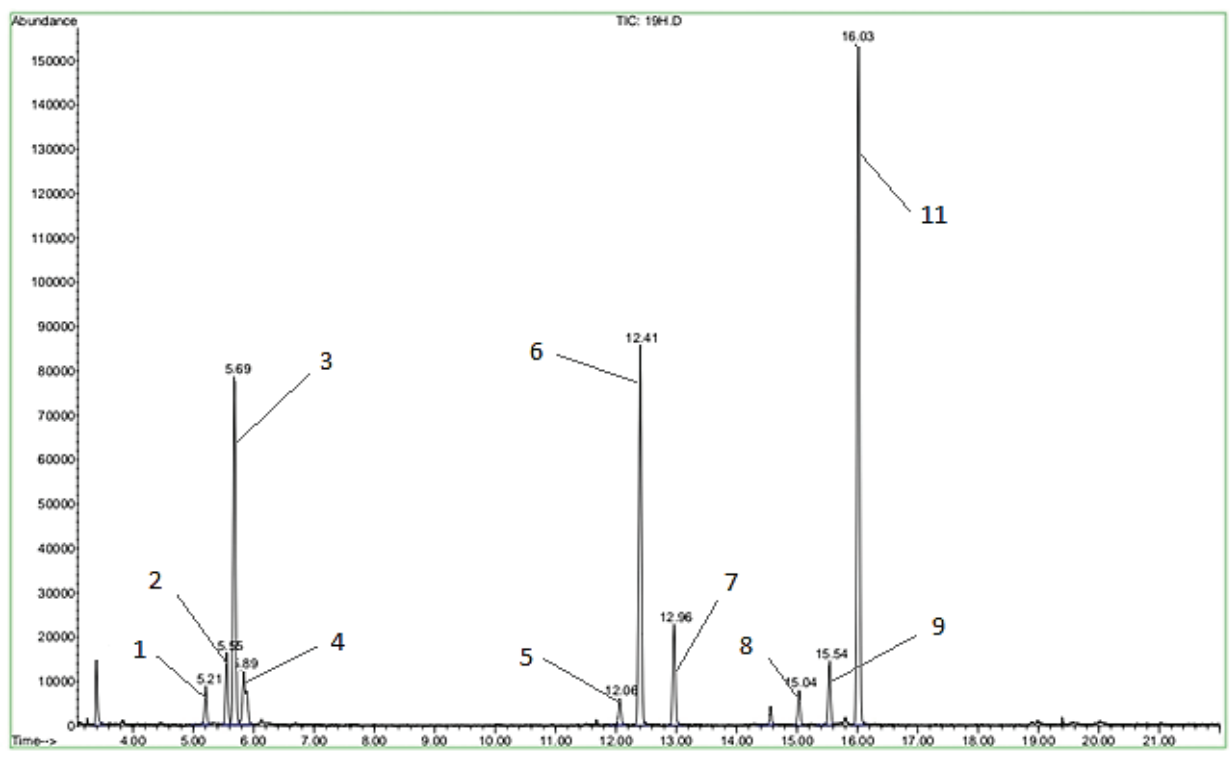

Fig. 10. GC-MS chromatogram of carbohydrates after hydrolysis of sample 5, after derivatization. The keys to the peaks are in Table II. 


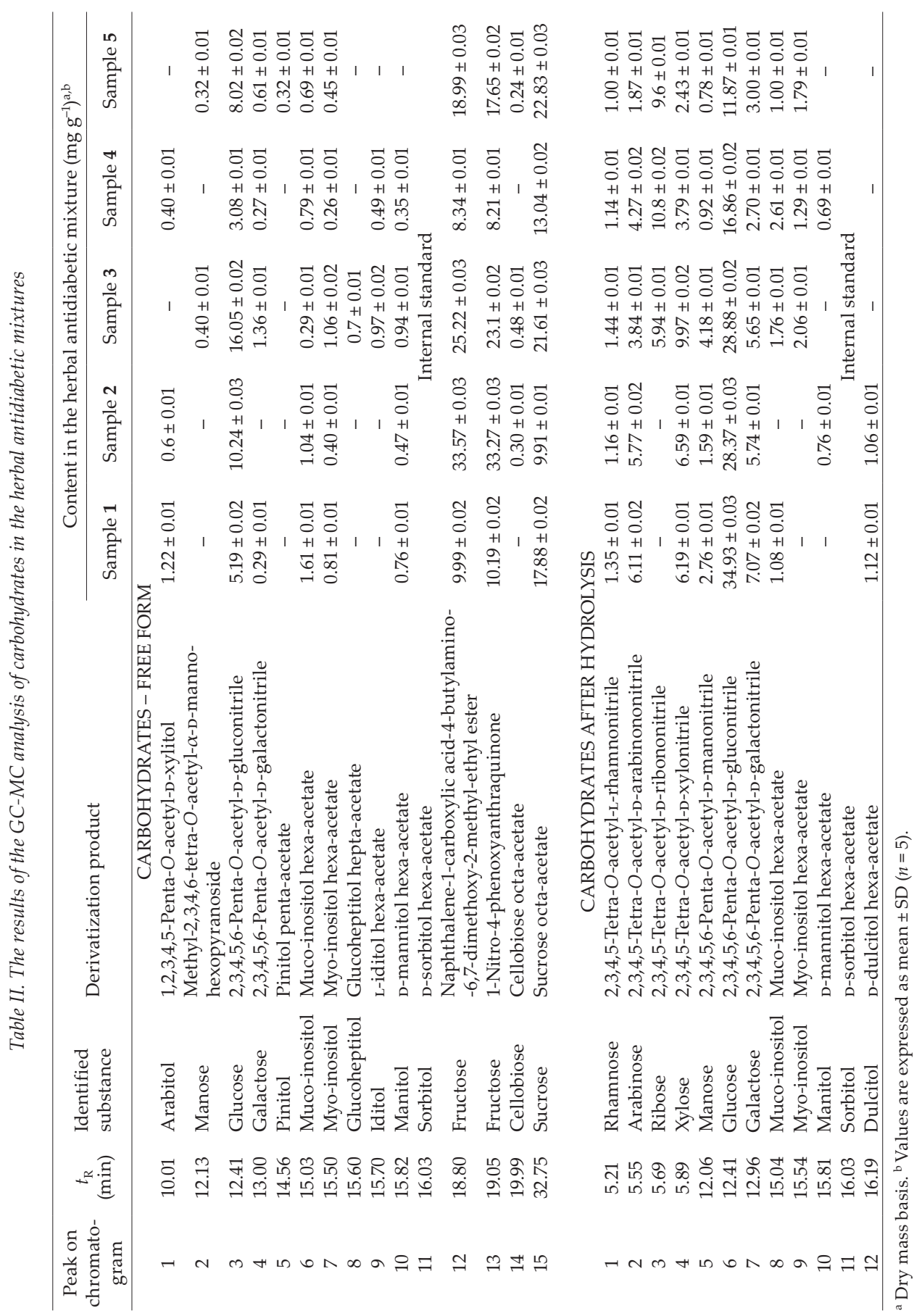


GC-MC analysis of bound carbohydrates showed, after hydrolysis, that the largest number of carbohydrate monomers was present in sample 4, ten of them, samples 3 and 5 contained nine carbohydrates and samples 1 and 2 contained eight. The analyses showed that the hydrolysis of bound carbohydrates from all samples led to cleavage with the predominant formation of monosaccharides. Seven monosaccharides in the samples 3, 4 and 5 , and six monosaccharides in the samples 1 and 2 were identified after hydrolysis. In addition, the hydrolysis of bound carbohydrates led to the formation of polyalcohols, of which two were found in samples 1, 2, 3 and 5, and three polyalcohols in sample 4 (Figs. 2, $4,6,8,10)$.

Eight carbohydrates in the free form (four polyalcohols - arabitol, muco-inositol, myoinositol, mannitol, three monosaccharides - glucose, galactose, fructose and one disaccharide - sucrose), and eight in the bound form (two polyalcohols - muco-inositol, dulcitol and six monosaccharides - rhamnose, arabinose, xylose, mannose, glucose, galactose) were found in sample 1, similarly, eight carbohydrates in the free form (four polyalcohols arabitol, muco-inositol, myo-inositol, mannitol, two monosaccharides - glucose and fructose and two disaccharides - sucrose and cellobiose), and eight in the bound form (two polyalcohols - mannitol, dulcitol and six monosaccharides - rhamnose, arabinose, xylose, mannose, glucose, galactose) were detected in sample 2. Eleven carbohydrates in the free form (five polyalcohols - muco-inositol, myo-inositol, glucoheptitol, iditol, mannitol, four monosaccharides - mannose, glucose, galactose, fructose and two disaccharides - sucrose and cellobiose), and nine in the bound form (two polyalcohols - muco-inositol, myo-inositol and seven monosaccharides - rhamnose, arabinose, ribose, xylose, mannose, glucose, galactose) characterized sample 3, nine carbohydrates in the free form (five polyalcohols - muco-inositol, myo-inositol, iditol, mannitol, arabitol, three monosaccharides - glucose, galactose, fructose and one disaccharide - sucrose), and ten in the bound form (three polyalcohols - muco-inositol, myo-inositol, mannitol and seven monosaccharides - rhamnose, arabinose, ribose, xylose, mannose, glucose, galactose) were identified in sample 4. Also, in sample 5 nine carbohydrates in the free form were found (three polyalcohols - pinitol, muco-inositol, myo-inositol, four monosaccharides - mannose, glucose, galactose, fructose and two disaccharides - sucrose and cellobiose), and nine in the bound form (two polyalcohols - muco-inositol, myo-inositol and seven monosaccharides - rhamnose, arabinose, ribose, xylose, mannose, glucose, galactose). All these data are evident from Table II.

\section{Quantitative analyses}

Quantitative analyses of free carbohydrates showed that the predominant sugar was fructose; its content was (in $\mathrm{mg} \mathrm{g}^{-1}$ ): 20.18, 66.84, 48.32, 16.55 and 36.64 in sample 1-5, resp. High content (in $\mathrm{mg} \mathrm{g}^{-1}$ ) of glucose of 5.19, 10.24, 16.05, 3.08, 8.02, and of disaccharide, sucrose, of 17.88, 9.91, 21.61, 13.04 and 22.83 was estimated in samples $1-5$, resp. (Table II). Quantitations of carbohydrates after hydrolysis showed that the predominant monosaccharide was glucose (in $\mathrm{mg} \mathrm{g}^{-1}$ ): 34.93, 28.37, 28.88, 16.86 and 11.87 found in samples 1-5, resp. (Table II).

The chromatographic study revealed a number of sugar alcohols, which are often used as sweeteners for diabetics because they are energetically lower, are partially absorbed from the small intestine and not metabolized. Most often, mannitol is used as a sugar substitute owing to its low-calorie content (1.6 calories per gram) (28) and our research 
showed that investigated herbal mixtures contain this polyol in free form (samples 1, 2, 3 and 4) and bound form (samples 2 and 4) (Table II). Pinitol - a cyclic polyol, was identified and quantified $\left(0.32 \mathrm{mg} \mathrm{g}^{-1}\right)$ in sample 5 (Table II). Pinitol is known as an antidiabetic agent that has a hypoglycemic effect, reduces lipid peroxidation, protects liver, kidneys and pancreas (29). Myo-inositol, which is present in all samples of the antidiabetic mixtures in the free form and in the samples 3, 4 and 5 in the bound form (Table II), together with D-chiro-inositol are two inositol stereoisomers, which are acting like insulin mediators. These polyalcohols are involved in increasing insulin sensitivity of body tissues, which reduces insulin resistance as one of the main pathogenetic mechanisms of development of diabetes mellitus type $2(30,31)$.

\section{CONCLUSIONS}

The qualitative composition of carbohydrates both in free and bound form, as well as their quantitative contents in five herbal antidiabetic mixtures used in folk medicine for prevention and treatment of diabetes mellitus type 2 were analyzed by GC-MS.

Free carbohydrates and the monomers after hydrolysis of bound carbohydrates, as well as a number of polyalcohols, were quantified. The chromatographic analysis of carbohydrates in the herbal antidiabetic mixtures launched them as perspective herbal medicines for the prevention and treatment of diabetes mellitus and its complications. This research allows us to predict their possible use for optimization of antidiabetic pharmacotherapy, with the advisability of their further phytochemical and pharmacological research.

\section{REFERENCES}

1. M. Sakamoto, Type 2 diabetes and glycemic variability: various parameters in clinical practice, $J$. Clin. Med. Res. 10 (2018) 737-742; https://doi.org/10.14740/jocmr3556w

2. International Diabetes Federation, IDF Diabetes Atlas, 9th ed., Brussels 2019; http://www.diabetesatlas.org

3. S. Gothai, P. Ganesan, S.-Y. Park, S. Fakurazi, D.-K. Choi and P. Arulselvan, Natural phyto-bioactive compounds for the treatment of type 2 diabetes: inflammation as a target, Nutrients 8 (2016) Article ID 461; https://doi.org/10.3390/nu8080461

4. P. Governa, G. Baini, V. Borgonetti, G. Cettolin, D. Giachetti, A. R. Magnano, E. Miraldi and M. Biagi, Phytotherapy in the management of diabetes: A review, Molecules 23 (2018) Article ID 105; https://doi.org/10.3390/molecules23010105

5. Y. S. Oh and H. S. Jun, Role of bioactive food components in diabetes prevention: effects on betacell function and preservation, Nutr. Metab. Ins. 7 (2014) 51-59; https://doi.org/10.4137/NMI.S13589

6. W. Kooti, M. Farokhipour, Z. Asadzadeh, D. Ashtary-Larky and M. Asadi-Samani, The role of medicinal plants in the treatment of diabetes: a systematic review, Electr. Phys. 8 (2016) 1832-1842; https://doi.org/10.19082/1832

7. J. S. Skyler, G. L. Bakris, E. Bonifacio, T. Darsow, R. H. Eckel, L. Groop, P. H. Groop, Y. Handelsman, R. A. Inse, C. Mathieu, A. T. McElvaine, J. P. Palmer, A. Pugliese, D. A. Schatz, J. M. Sosenko, J. P. Wilding and R. E. Ratner, Differentiation of diabetes by pathophysiology, Nat. Hist. Progn. Diab. 66 (2017) 241-255; https://doi.org/10.2337/db16-0806 
8. A. O. Savych, S. M. Marchyshyn, H. R. Kozyr and O. Y. Skrinchuk, Basic principles for the using of medicinal plants and their mixtures for the treatment and prevention of diabetes type 2, J. Phytother. 4 (2019) 43-46: https://doi.org/10.33617/2522-9680-2019-4-43.

9. Y. S. Tovstuha, Golden Recipes of Ukrainian Folk Medicine, Kraina Mriy Publishers, Kyiv 2010, pp. 550.

10. K. Ganesan and B. Xu, Anti-diabetic effects and mechanisms of dietary polysaccharides, Molecules 24 (2019) Article ID 2556; https://doi.org/10.3390/molecules24142556

11. X. Chen, L. Qian, B. Wang, Z. Zhang, H. Liu, Y. Zhang and J. Liu, Synergistic hypoglycemic effects of pumpkin polysaccharides and puerarin on type II diabetes mellitus mice, Molecules 24 (2019) Article ID 955; https://doi.org/10.3390/molecules24050955

12. X. Cui, S. Wang, H. Cao, H. Guo, Y. Li, F. Xu, M. Zheng, X. Xi and C. Han, A Review: The bioactivities and pharmacological applications of Polygonatum sibiricum polysaccharides, Molecules 23 (2018) Article ID 1170; https://doi.org/10.3390/molecules23051170

13. J.-F. Cui, H. Ye, Y.-J. Zhu, Y.-P. Li, J.-F. Wang and P. Wang, Characterization and hypoglycemic activity of a rhamnan-type sulfated polysaccharide derivative, Mar. Drug. 17 (2019) Article ID 21 (14 pages); https://doi.org/10.3390/md17010021

14. Y. Luo, B. Peng, W. Wei, X. Tian and Z. Wu, Antioxidant and anti-diabetic activities of polysaccharides from guava leaves, Molecules 24 (2019) Article ID 1343; https://doi.org/10.3390/ molecules24071343

15. T. Zhang, Y. Yang, Y. Liang, X. Jiao and C. Zhao, Beneficial effect of intestinal fermentation of natural polysaccharides, Nutrients 10 (2018) Article ID 1055; https://doi.org/10.3390/nu10081055

16. D.-T. Wu, W. Liu, Q.-H. Han, P. Wang, X.-R. Xiang, Y. Ding, L. Zhao, Q. Zhang, S.-Q. Li and W. Qin, Extraction optimization, structural characterization, and antioxidant activities of polysaccharides from Cassia seed (Cassia obtusifolia), Molecules 24 (2019) Article ID 2817; https://doi.org/10.3390/ molecules 24152817

17. J. He, Y. Xu, H. Chen and P. Sun, Extraction, structural characterization, and potential antioxidant activity of the polysaccharides from four seaweeds, Int. J. Mol. Sci. 17 (2016) Article ID 1988; https://doi.org/10.3390/ijms17121988

18. R. Mistry, F. Gu, H. A. Schols, H. J. Verkade and U. Tietge, Effect of the prebiotic fiber inulin on cholesterol metabolism in wildtype mice, Sci. Rep. 8 (2018) Article ID 13238; https://doi.org/10.1038/ s41598-018-31698-7

19. Y. Yuan, Q. Liu, F. Zhao, J. Cao, X. Shen and C. Li, Holothuria leucospilota polysaccharides ameliorate hyperlipidemia in high-fat diet-induced rats via short-chain fatty acids production and lipid metabolism regulation, Int. J. Mol. Sci. 20 (2019) Article ID 4738; https://doi.org/10.3390/ijms20194738

20. Y. Neelakandan and A. Venkatesan, Antinociceptive and anti-inflammatory effect of sulfated polysaccharide fractions from Sargassum wightii and Halophila ovalis in male Wistar rats, Indian J. Pharmacol. 48 (2016) 562-570; https://doi.org/10.4103/0253-7613.190754

21. A. O. Savych and S. M. Marchyshyn, Investigation of hypoglycemic activity of herbal antidiabetic mixtures widely used in folk medicine on normoglycemic animals, $V$ All-Ukrainian ScientificPractical Conference with International Participation «Chemistry of Natural Compounds», Ternopil State Medical University Publishers, Ternopil 2019, pp. 108-109.

22. A. O. Savych and S. M. Marchyshyn, Investigation of antihyperglycemic activity of herbal antidiabetic mixtures used in folk medicine under conditions of alimentary hyperglycemia in rats, Scientific and Practical Internet-conference «Top Issues of Clinical Pharmacology and Clinical Pharmacy», National Pharmaceutical University Publishers, Kharkiv 2019, pp. 278-279.

23. A. O. Savych and S. M. Marchyshyn, Screening study of antihyperglycemic activity of herbal antidiabetic mixtures used in folk medicine, International Scientific-Practical Conference Dedicated 
to the Memory of Doctor of Chemical Sciences, Professor Nina Maksyutina (to the 95th Anniversary). Planta+. Achievements and Prospects, Palyvoda Publishers, Kyiv 2020, pp. 222-224.

24. World Health Organization, WHO Guidelines on Good Agricultural and Mixture Practices (GACP) for Medicinal Plants, WHO, Geneva 2003, pp. 72; https://apps.who.int/iris/handle/10665/42783; August 29, 2019.

25. Y. F. Chen, M.-Y. Xie, Y.-X. Wang, S.-P. Nie and C. Li, Analysis of the monosaccharide composition of purified polysaccharides in Ganoderma atrum by capillary gas chromatography, J. Phytochem. Anal. 20 (2009) 503-510; https://doi.org/10.1002/pca.1153

26. J. Guan, F.-Q. Yang and S.-P. Li, Evaluation of carbohydrates in natural and cultured Cordyceps by pressurized liquid extraction and gas chromatography coupled with mass spectrometry, Molecules 15 (2010) 4227-4241; https://doi.org/10.3390/molecules15064227

27. C. Agius, S. Tucher, B. Poppenberger and W. Rozhon, Quantification of sugars and organic acids in tomato fruits, MethodsX 5 (2018) 537-550; https://doi.org/10.1016/j.mex.2018.05.014

28. M. Gupta, Sugar substitutes: mechanism, availability, current use and safety concerns-an update, Mac. J. Med. Sci. 6 (2018) 1888-1894; https://doi.org/10.3889/oamjms.2018.336

29. S. H. Bates, R. B. Jones and C. J. Bailey, Insulin-like effect of pinitol, Br. J. Pharmacol. 130 (2000) 1944-1948; https://doi.org/10.1038/sj.bjp.0703523

30. D. R. Chhetri, Myo-inositol and its derivatives: Their emerging role in the treatment of human diseases, Front. Pharmacol.10 (2019) Article ID 1172 (8 pages); https://doi.org/10.3389/fphar.2019.01172

31. E. Benelli, S. Del Ghianda, C. Di Cosmo and M. Tonacchera, A combined therapy with myoinositol and D-chiro-inositol improves endocrine parameters and insulin resistance in PCOS young overweight women, Int. J. Endocrinol. 2016 (2016) Article ID 3204083 (5 pages); https://doi. org/10.1155/2016/3204083 